\title{
Fatores de risco associados à soropositividade para leptospirose em matrizes suínas
}

\author{
Risk factors associated to leptospirosis seropositiveness in sows
}

\author{
Ádina Cléia Botazzo Delbem ${ }^{1}$ Roberta Lemos Freire ${ }^{2}$ Caio Abércio da Silva ${ }^{3}$ \\ Ernst Eckehardt Müller ${ }^{2}$ Ricardo Augusto Dias ${ }^{5}$ José Soares Ferreira Neto $^{4}$ \\ Julio Cesar de Freitas ${ }^{2 *}$
}

RESUMO

\begin{abstract}
A leptospirose é uma zoonose amplamente difundida e de grande importância sócio-econômica para a suinocultura. Com o objetivo de individualizar condutas de manejo ou condições ambientais que estejam relacionadas ao risco de infecção por leptospirose, foram estudadas 298 matrizes suínas provenientes de granjas da região norte do Estado do Paraná. Todos os animais foram submetidos à prova de soroaglutinação microscópica e para cada um deles foi aplicado um questionário epidemiológico, que procurou investigar variáveis que poderiam estar associadas a essa infecção. Os resultados obtidos foram submetidos ao teste (2, seguido de análise multivariada. Foram detectados títulos de anticorpos $\geqslant 100$ em 132 matrizes suinas (44,3\%), sendo em maior freqüencia contra o sorovar icterohaemorrhagiae (98,5\%). O modelo final da análise multivariada apontou como fatores de risco para a leptospirose a existência de áreas alagadiças próxima às instalações $(O R=1,73 ; 1,04 \leqslant I C 95 \%<2,80)$, o uso de bebedouro do tipo canaleta $(O R=1,58 ; 0,98 \leqslant I C 95 \% \leqslant 2,55)$ e a inexistência de higienização do reservatório de água $(O R=2,25 ; 0,79 \leqslant$ IC95\% $\leqslant 6,43$ ).
\end{abstract}

Palavras-chave: leptospirose, matrizes suínas, fatores de risco, diagnóstico.

\section{ABSTRACT}

Leptospirosis is a widespread zoonosis of great social and economic importance for swine production system. Two hundred and ninety-eight sows from farms in the north of
Paraná state, Brazil were studied to individualize management practices or environmental condition that are related to risk of leptospirosis infection. All the animals were submitted to the microscopic seroaglutination test and an epidemiological questionnaire was filled out for each one to investigate variables that could be associated with this infection. The results were submitted to the $c^{2}$ test, followed by multivariate analysis. Antibody titers of $\geq 100$ were detected in 132 sows (44.3\%) most frequently against icterohaemorrhagiae serovar (98.5\%). The final model of multivariate analysis showed the risk factors to be flooded areas near the installation $(O R=1.73$; $1.04 \leqslant I C 95 \% \leqslant 2.80)$, canal type water source $(O R=1.58$; $0.98 \leqslant I C 95 \% \leqslant 2.55)$ and absence of cleaning of the water reservoirs $(O R=2.25 ; 0.72 \leqslant I C 95 \% \leqslant 6.43)$.

Key words: leptospirosis, sows, risk factors, diagnostic

\section{INTRODUÇÃO}

A leptospirose é uma zoonose de ampla distribuição geográfica, geralmente de caráter ocupacional, representando risco para a saúde pública, principalmente para médicos veterinários, magarefes e funcionários de granjas suínas que estão sujeitos ao contágio direto com o agente (FARR, 1995; FAINE et al., 1999). CAMPAGNOLO et al. (2000), estudando um surto de leptospirose suína, verificaram que havia

\footnotetext{
${ }^{1}$ Médico Veterinário, Aluno de Pós- graduação do Departamento de Medicina Veterinária Preventiva; Centro de Ciências Agrárias (CCA), Universidade Estadual de Londrina (UEL), Londrina, Paraná, Brasil.

${ }^{2}$ Médico Veterinário, Doutor, Professor do Departamento de Medicina Veterinária Preventiva, CCA, UEL.

${ }^{3}$ Médico Veterinário, Doutor, Professor do Departamento de Zootecnia, CCA, UEL.

${ }^{4}$ Médico Veterinário, Doutor, Professor do Departamento de Medicina Veterinária Preventiva e Saúde Animal, Faculdade de Medicina Veterinária e Zootecnia (FMVZ), Universidade de São Paulo (USP), São Paulo, SP., Brasil.

${ }^{5}$ Médico Veterinário, Mestre, Aluno de Pós-graduação do Departamento de Medicina Veterinária Preventiva e Saúde Animal, FMVZ, USP.

*Autor para correspondência:Prof. Dr. Julio Cesar de Freitas, Rodovia Celso Garcia Cid (PR 445), km 380, CP 6001. 86051-990. Tel.: (43)

371-4765; Fax: (43) 371-4714. E-mail: freitasj@uel.br
} 
uma associação entre humanos expostos e animais infectados. Esses autores verificaram que indivíduos que trabalhavam com suínos reagentes e que fumavam e bebiam durante suas atividades com os animais, estavam sujeitos a um risco 14,4 e 5,1 vezes maior de se infectar, respectivamente.

De acordo com o OFFICE INTERNATIONAL DES ÉPIZOOTIES (1992), a leptospirose está classificada como uma enfermidade da lista B, grupo ao qual pertencem as doenças transmissíveis de grande importância do ponto de vista sócioeconômico e/ou sanitário, cuja repercussão no comércio internacional de animais e produtos de origem animal são consideráveis (BLAHA, 1989).

Nos suínos, a leptospirose caracteriza-se pela ocorrência de abortamento no terço final de gestação, repetição de cio, mumificação fetal, natimortalidade, nascimento de leitões fracos, baixo número de leitões, descarga vulvar e morte embrionária (ELLIS, 1989).

O controle da leptospirose suína é baseado na imunização de suscetíveis, nas ações sobre as fontes de infecção visando à diminuição da quantidade de leptospiras lançadas no ambiente e na identificação e eliminação dos fatores que ampliam a sobrevivência do agente no ambiente (GUIMARÃES et al., 1982/ 1983).

A imunização deve ser feita com os sorovares de leptospiras presentes na região. A diminuição da quantidade de leptospiras lançadas no ambiente é conseguida através de ações dirigidas aos reservatórios, principalmente roedores, e também pelo tratamento massal com antibiótico para eliminação dos portadores renais (FAINE et al., 1999). Os fatores ambientais, que ampliam a sobrevivência do agente na ausência de parasitismo e aumentam o risco de infecção, são muito variáveis e estão relacionados, basicamente, ao manejo da água dentro das granjas. Portanto, dependendo do tipo de exploração e das práticas de manejo adotadas, esses fatores condicionantes para a leptospirose podem também variar.

O objetivo deste trabalho foi identificar condutas de manejo ou condições ambientais relacionadas à maior freqüência de animais soropositivos à leptospira, ou seja, ao maior risco de infecção.

\section{MATERIAL E MÉTODOS}

\section{Animais}

Foram estudadas 298 matrizes, oriundas de 22 granjas de ciclo completo, com e sem histórico de problemas reprodutivos, vacinadas ou não contra leptospirose, da região norte do Estado do Paraná.

\section{Colheita do sangue}

O sangue foi colhido através da punção da veia cava cranial. O soro obtido foi acondicionado em frascos estéreis, e mantidos à $-20^{\circ} \mathrm{C}$. Nas granjas onde se praticava a vacinação contra leptospirose, as matrizes foram sangradas somente depois de quatro meses da última vacinação.

\section{Soroaglutinação microscópica (SAM)}

$O$ teste de soroaglutinação microscópica (SAM) foi realizado segundo RYU (1970). Foram utilizadas culturas vivas de 22 sorovares de Leptospira spp: australis (Ballico), bratislava (Jez bratislava), autumnalis (Akiyami A), butembo (Butembo), fortbragg (Fort Bragg), castellonis (Castellon 3), bataviae (Van Tienen), canicola (Hond Utretcht), whitcombi (Whitcombi), cynopteri (3522 C), sentot (Sentot), grippotyphosa (Moskva V), hebdomadis (Hebdomadis), copenhageni (M 20), icterohaemorrhagiae (RGA), panama (CZ 214 K), pomona (Pomona), pyrogenes (Salinem), wolffi (3705), hardjo (Hardjoprajitno), shermani (1342 K) e tarassovi (perepelitsin).

As culturas foram mantidas entre cinco e dez dias a $28^{\circ} \mathrm{C}$ em meio de Ellighausen (EMJH) enriquecido com soro de coelho. Os soros, diluídos inicialmente a 1:100, foram testados frente a todos os antígenos, e aqueles que apresentaram aglutinação nessa diluição foram titulados. A leitura foi realizada em microscópio de campo escuro de acordo com MYERS (1985).

A interpretação dos resultados sorológicos obedeceu o critério do sorovar mais provável. conforme VASCONCELLOS et al. (1997). Para um único animal, o sorovar mais provável é aquele para o qual a reação de soroaglutinação microscópica apresentou o maior título; para um grupo de animais, o sorovar mais provável é aquele que apresentou maior freqüência quando computados os resultados individuais; os resultados que apresentaram o mesmo título para mais de um sorovar foram desconsiderados da análise.

\section{Variáveis estudadas \\ Variáveis relacionadas às matrizes}

As fichas continham dados referentes à origem do animal de reposição (se adquirido de granja não controlada ou selecionado na granja) e utilização de monta natural ou inseminação artificial. 


\section{Variáveis relacionadas ao SPS}

Foram estudados os sistemas de criação (intensivo, semi-intensivo e extensivo); a origem das rações (comercial ou produzida na granja); armazenamento da ração (silos, embalagens em contato com o piso ou suspensos); origem da água (riacho, mina, poço artesiano ou poço comum); presença de tampa no reservatório de água; acesso de outras espécies animais ao reservatório de água; bebedouro tipo canaleta ou automático; ração fornecida em cocho convencional ou no chão; acesso de outros animais ao cocho; presença de roedores na granja; higienização diária das instalações; uso de lâmina d' água na granja; presença de áreas alagadiças na granja numa distância máxima de cinco metros das instalações; separação de funcionários por área; histórico de problema reprodutivo na propriedade; descarte de reprodutores por problema reprodutivo; número de matrizes na granja; vizinhança com outras granjas suínas e a localização (urbana ou rural).

\section{Análise estatística}

As matrizes foram divididas em dois grupos: soropositivas e soronegativas. Para verificar se esses dois grupos eram homogêneos quanto à idade e condição vacinal, a média da idade das matrizes foi comparada pelo teste $t$ de Student e a proporção de animais vacinados foi comparada pelo teste de duas proporções. Cada uma das 30 variáveis estudadas foi submetida ao teste $\chi^{2}$, e aquelas com $\mathrm{p} \leqslant 0,2$ foram oferecidas à regressão logística multivariada. Todas as análises foram realizadas com o auxílio do programa SPSS.

\section{RESULTADOS}

Dentre todas as amostras examinadas, foi detectada uma soropositividade de 44,3\% (132/298) para leptospirose. Para os animais soropositivos, o sorovar mais provável predominante foi o icterohaemorrhagiae (130/132), seguido por sentot (2/ 132). Todas as granjas apresentaram suínos soropositivos, com títulos iguais a 100, cuja freqüência variou entre $20 \%$ e $77,3 \%$.

A idade e a condição vacinal das matrizes foram comparadas entre os grupos de soropositivos e soronegativos, e os resultados constam na tabela 1 .

A tabela 2 traz as variáveis estudadas e o resultado da análise univariada. A tabela 3 mostra o modelo final da regressão logística multivariada.

\section{DISCUSSÃO}

No Brasil, LANGONI et al. (1995) e GIRIO et al. (1998), examinando amostras colhidas em abatedouro, encontraram anticorpos contra leptospira nas proporções de 27,39\% (66/241) e 70,8\% (112/ 158), respectivamente.

A primeira investigação sorológica em suínos do Estado do Paraná foi realizada por ENRIETTI, em 1954, que não encontrou nenhum soropositivo dentre os 153 animais examinados. Em 1974, DUTRA refere uma prevalência de 37,13\% (344/929) para os suínos do mesmo Estado.

No presente estudo, a freqüência de suínos sororreatores para leptospirose foi de 44,3\% (132/ 298). Esses resultados indicam que a infecção por leptospiras ocorre em freqüências importantes nos rebanhos suínos brasileiros e que essas freqüências variam com a região estudada.

Dentre os animais soropositivos, o sorovar icterohaemorrhagiae foi identificado como o mais provável em 98,5\% (130/132) das oportunidades. O papel desse sorovar como causador de problemas reprodutivos tem sido investigado por alguns autores (FERREIRANETO et al., 1997; VAN TIL \& DOHOO, 1991).

É digno de nota a ausência de animais sororreatores para os sorovares pomona e bratislava, importantes causadores de transtornos reprodutivos em suínos (CHAPPEL et al., 1992; ELLIS, 1999). GIRIO et al. (1998) verificaram uma baixa freqüência de suínos sororreatores (05/112) para o sorovar pomona no Estado de São Paulo. No Brasil, até 1995, apenas no Rio Grande do Sul haviam sido encontrados suínos

Tabela 1 - Comparação entre os grupos de matrizes suínas quanto à idade e à proporção de animais vacinados contra leptospirose.

\begin{tabular}{lccc}
\hline Variáveis & Matrizes soropositivas & Matrizes soronegativas & Valores de p \\
\hline Média das idades em meses & 27,5 & 28,7 & $0,46^{*}$ \\
Proporção de vacinados & $127 / 147$ & $133 / 151$ & $0,66^{* *}$ \\
\hline
\end{tabular}

*Teste $t$ de Student.

** Teste de comparação de duas proporções. 
Tabela 2 - Resultado do teste $\chi^{2}$ para as variáveis tidas como possíveis fatores de risco para a soropositividade para leptospirose em matrizes suínas

\begin{tabular}{|c|c|c|c|}
\hline Variáveis & Matrizes soropositivas & Matrizes soronegativas & Valores de $\mathrm{p}$ \\
\hline Matriz adquirida de granja multiplicadora & $15 / 147$ & $39 / 151$ & 0,178 \\
\hline Faz cobertura por monta natural & $147 / 147$ & $150 / 151$ & 1,000 \\
\hline Faz descarte de reprodutores por problema reprodutivo & $50 / 147$ & $62 / 151$ & 0,209 \\
\hline Funcionários não são separados por área & $130 / 147$ & $131 / 151$ & 0,660 \\
\hline Número de matrizes superior a 39 & $63 / 147$ & $53 / 151$ & 0,170 \\
\hline Não tem programa de higienização e desinfecção & $57 / 147$ & $63 / 151$ & 0,604 \\
\hline Matrizes têm acesso a piquetes & $17 / 147$ & $13 / 151$ & 0,397 \\
\hline Não controla roedores & $32 / 147$ & $30 / 151$ & 0,020 \\
\hline Água oferecida às matrizes provém de poço & $99 / 147$ & $90 / 151$ & 0,165 \\
\hline Reservatório de água sem tampa & $147 / 147$ & $02 / 151$ & 0,375 \\
\hline Outras espécies animais têm acesso ao reservatório de água & $46 / 147$ & $57 / 151$ & 0,241 \\
\hline Roedores têm acesso ao reservatório de água & $46 / 147$ & $57 / 151$ & 0,241 \\
\hline Cães têm acesso ao reservatório de água & $1 / 147$ & $1 / 151$ & 1,000 \\
\hline Felinos têm acesso ao reservatório de água & $12 / 147$ & $7 / 151$ & 0,213 \\
\hline Bebedouro é do tipo canaleta & $81 / 147$ & $63 / 151$ & 0,021 \\
\hline Presença de lâmina d’água & $38 / 147$ & $49 / 151$ & 0,210 \\
\hline Não há higienização sistemática do reservatório de água & $141 / 147$ & $138 / 151$ & 0,110 \\
\hline Existência de áreas alagadiças na propriedade & $92 / 147$ & $78 / 151$ & 0,057 \\
\hline Ração é produzida na granja & $68 / 147$ & $87 / 151$ & 0,050 \\
\hline Sacos de ração são estocados diretamente sobre o chão & $143 / 147$ & $151 / 151$ & 0,058 \\
\hline Ração é fornecida em cocho convencional ou no chão & $147 / 147$ & $150 / 151$ & 1,000 \\
\hline Outras espécies animais têm acesso ao cocho de ração & $140 / 147$ & $141 / 151$ & 0,489 \\
\hline Roedores têm acesso ao cocho de ração & $132 / 147$ & $132 / 151$ & 0,518 \\
\hline Cães têm acesso ao cocho de ração & $81 / 147$ & $64 / 151$ & 0,280 \\
\hline Felinos têm acesso ao cocho de ração & $59 / 147$ & $62 / 151$ & 0,871 \\
\hline Propriedade com histórico de problema reprodutivo & $108 / 147$ & $98 / 151$ & 0,109 \\
\hline Propriedade localizada no perímetro urbano & $33 / 147$ & $28 / 151$ & 0,403 \\
\hline Propriedade faz divisa com outra granja suína & $55 / 147$ & $58 / 151$ & 0,859 \\
\hline
\end{tabular}

sororreatores para o sorovar bratislava (OLIVEIRA et al.,1995).

Os resultados da tabela 1 mostram que os dois grupos de matrizes estudadas são homogêneos quanto à idade e condição vacinal, ou seja, os grupos de matrizes soropositivas e soronegativas têm a mesma proporção de animais vacinados e idades médias iguais. Essas variáveis poderiam significar um viés na composição desses grupos. É razoável supor que quanto maior a idade do animal, maior é a chance de ele ser exposto ao agente. Embora as colheitas nas granjas que praticavam vacinação contra leptospirose tenham sido feitas no mínimo quatro meses após a última aplicação da vacina, tempo suficiente para que os anticorpos vacinais não sejam detectados pela SAM (FAINE et al., 1999), foi tomado o cuidado adicional de garantir a mesma proporção de matrizes vacinadas nos dois grupos.

O modelo final da regressão logística (tabela 3) apontou três variáveis associadas à soropositividade para leptospirose: o bebedouro tipo canaleta, a existência de área alagadiça próxima às instalações dos suínos e a falta de higienização sistemática do reservatório de água. Os resultados dessa tabela mostram que tomar água em bebedouro tipo canaleta significa um risco 1,58 vezes maior de ser sororreator para leptospirose do que tomar água em bebedouro automático; pertencer a uma propriedade onde existe área alagadiça próxima às instalações significa um risco 1,73 vezes maior de ser sororreator; não ter o reservatório de água regularmente higienizado significa uma chance 2,25 vezes maior de ser sororreator do que tê-lo sistematicamente limpo. Ressalte-se que a Odds Ratio da variável "não higienização sistemática do reservatório de água" não foi estatisticamente diferente de um, porém apresentou-se com uma tendência de ser maior que um $(0,79 \leqslant \operatorname{IC} 95 \% \leqslant 6,43)$, além de ser biologicamente plausível. 
Tabela 3 - Modelo final da regressão logística para fatores de risco associados à soropositividade de matrizes suínas para leptospirose.

\begin{tabular}{lccc}
\hline Fator de risco & Caso & Controle & OR \\
\hline Bebedouro tipo canaleta & $81 / 298$ & $63 / 298$ & 1,58 \\
Existência de áreas alagadiças & $92 / 298$ & $78 / 298$ & $0,98-2,55$ \\
Inexistência de higienização sistemática do reservatório de água & $141 / 298$ & $138 / 298$ & 1,73 \\
\hline
\end{tabular}

As três variáveis estão relacionadas à água, necessidade básica para sobrevivência das leptospiras (MURHEKAR et al., 1998), e todas elas podem ser consideradas modalidades de água parada. Curiosamente, a variável "presença de lâmina d'água" apresentou $\mathrm{p}=0,21$ para o teste $\chi^{2}$, e não foi selecionada para a análise multivariada. É provável que essa variável não esteja associada à soropositividade para leptospirose por ser uma prática de manejo que envolve a utilização de água corrente e não parada. ANDRE \& GARNIERE (1990) mostraram que a água é o fator epidemiológico mais importante da leptospirose e a presença de água estagnada próximo às baias dos suínos seria o principal meio de transmissão (BECKER \& BUERGELT, 1998; PAZSOLDAN et al., 1991). DOUGLIN et al. (1997) observaram que pessoas que caminham em áreas com água estagnada ou poças têm 25,62 vezes mais chance de ser reagente para leptospirose.

O predomínio de sororreatores para o sorovar icterohaemorrhagiae sugere fortemente que as fontes de infecção envolvidas sejam os roedores. A presença desses animais na granja foi investigada através de três perguntas do questionário, duas inquirindo sobe o avistamento desses animais, e uma terceira, inquirindo sobre a não realização de controle de roedores. Apenas a variável "não controla roedores" $(\mathrm{p}=0,02)$ foi selecionada para a análise multivariada, porém não permaneceu no modelo final. Essa variável, acreditava-se, seria a que melhores chances teria de avaliar o contato com roedores, pois esperava-se que a maioria das granjas acusassem a presença desses animais. Essa suspeita foi confirmada pelos resultados do questionário, quando se observam os dados relativos à variável "roedores têm acesso ao cocho de ração", na tabela 2 . O controle de roedores em granjas de suínos é tarefa complexa, existem várias estratégias, e vários níveis de controle podem ser adotados, com resultados bastante variáveis. Assim sendo, haveria necessidade de se medir a eficiência do programa de controle de roedores realizado pela granja, o que não foi feito. Portanto, a despeito de não ter emergido como fator de risco, acredita-se que a fonte de infecção mais importante tenham sido os roedores.
PIFFER et al. (1998) afirmaram que uma granja suína oferece múltiplas formas para a viabilidade, permanência e transmissão da leptospirose através de características favoráveis do ambiente, do manejo e das instalações. Os resultados do presente estudo sugerem que as leptospiras foram lançadas para o meio ambiente principalmente através da urina de roedores, e que esses agentes encontraram nas coleções de águas paradas, representadas por áreas alagadiças, bebedouros do tipo canaleta e reservatórios de água não higienizados periodicamente, condições para sobreviver e meios para alcançar um suíno suscetível.

Assim sendo, a sugestão de intervenção é a drenagem das áreas alagadiças próximas às instalações dos suínos, a substituição dos bebedouros do tipo canaleta pelos automáticos e a higienização periódica dos reservatórios de água. Quando não for possível a troca por bebedouros automáticos, sugere-se um programa de higienização periódica dos bebedouros do tipo canaleta, pois tal prática parece ter sido eficiente para os reservatórios de água. Adicionalmente, recomenda-se a adoção de programa de controle de roedores. Os resultados obtidos indicam que a lâmina d'água não está relacionada com aumento de risco de infecção por leptospiras.

\section{REFERÊNCIAS BIBLIOGRÁFICAS}

ANDRE-FONTAINE G.; GANIERE J.P. New topics on leptospirosis. Compendium of Immunological and Microbiological Infection Disease, v.13, p.163-168, 1990.

BECKER, H. N.; BUERGELT, C. Leptospirosis as a possible cause of reduced performance in market weight swine raised in dirt lots. In: INTERNATIONAL PIG VETERINARY SCIENCE, 10., Rio de Janeiro. Anais... Rio de Janeiro, RJ, 1998. p. 143.

BLAHA, T. Applied veterinary epidemiology. Amsterdam : Elsevier, 1989. p.95-103.

CAMPAGNOLO, E.R. et al. Analysis of the 1998 outbreak of leptospirosis in Missouri in humans exposed to infected swine. Journal American Veterinary Medical Association, v.216, p.676-682, 2000 .

CHAPPEL, R. J. et al. Comparison of diagnostic procedures for porcine leptospirosis. Veterinary Microbiological, v.30, p.151163, 1992.

Ciência Rural, v.34, n.3, mai-jun, 2004. 
DOUGLIN, C. P. et al. Risk factors for severe leptospirosis in the Parish of St. Andrew, Barbados. Emergence Infectious Disease, v.3, n.1, jan-mar., 1997. Capturado em 27 agosto 2000. Online. Disponível em http://www.cdc.gov/ncidod/eid/vol3nol/douglin.htm.

DUTRA, M. J. Incidência de leptospirose em suínos no Paraná. Arquivos de Biologia e Tecnologia, v.17, p.70-74, 1974.

ELLIS, W.A. Leptospira australis infection in pigs. Pig Veterinary Journal, v.22, p.83-92, 1989.

ELLIS, W.A. Leptospirosis. In: LEMAN, A.D. et al. Diseases of swine. 7.ed. Ames : Iowa State University, 1999. p.483-493.

ENRIETTI, M.A. Contribuição ao conhecimento da incidência de leptospiras em murídeos, caninos e suínos no Paraná. Arquivos de Biologia e Tecnologia, v.IX, art.3, p.21-72, 1954.

FAINE, S. et al. Leptospira and leptospirosis. 2.ed. Melbourne: Australia, MediSci, 1999. 272p.

FARR, R.W. Leptospirosis. Clinical Infectious Disease, v.21, p.1-6, 1995.

FERREIRA NETO, J.S. et al. Leptospira interrogans serovar icterohaemorrhagiae seropositivity and the reproductive performance of sows. Preventive Veterinary Medicine, v.31, p.87-93, 1997.

GIRIO, R.J.S. et al. Alterações reprodutivas, hematológicas e anatomopatológicas em fêmeas suínas com títulos de anticorpos contra Leptospira interrogans sorotipo icterohaemorrhagiae. Revista Brasileira de Ciências Veterinárias, v.5, p.99-103, 1998.

GUIAMARÃES, M.C. et al. Epidemiologia e controle da leptospirose bovina. Importância do portador renal e do seu controle terapêutico. Comunicações Científicas da Faculdade de Medicina Veterinária e Zootecnia da Universidade de São Paulo, v.6/7, n.1/4, p.21-34, 1982/1983.

LANGONI, H. et al. Inquérito soroepidemiológico para leptospirose suína. In: CONGRESSO BRASILEIRO DE VETERINÁRIOS ESPECIALISTAS EM SUÍNOS, 7., 1995, Blumenau, SC. Anais... Blumenau: ARAVES, 1995. p.153.
MURHEKAR, M.V. et al. Risk factors in the transmission of leptospiral infection. Indian Journal Medical Research, v.107, p.218-223, 1998.

MYERS, D. Leptospirosis: manual de métodos para el diagnostico de laboratório. Buenos Aires : Centro Panamericano de Zoonosis, OPS/OMS, 1985. 30p. (Nota técnica 30).

OFFICE INTERNATIONAL DES EPIZOOTIES (O.I.E). Manual of standars for diagnostic tests and vaccines. Leptospirosis (B6). 2.ed. Paris,[s/n], 1992. p.186-196.

OLIVEIRA, S.J. et al. Sorologia para diagnóstico de leptospirose em suínos no Rio Grande do Sul: resultados obtidos de granjas com e sem problemas de reprodução. Pesquisa Agropecuária Gaúcha, v.1, p.263-267, 1995.

PAZ-SOLDAN, S.V.; DIANDERAS, M.T.; WINDSOR, R.S. Leptospira interrogans serovar canicola: a causal agente of sow abortions in Arequipa, Peru. Tropical Animal Health Production, v.23, p.233-240, 1991.

PIFFER, I.A.; PERDOMO, C.C.; SOBESTIANSKY, J. Efeitos de fatores ambientais na ocorrência de doenças. In: SOBESTIANSKY, J. et al. Suinocultura Intensiva: produção, manejo e saúde do rebanho. Brasília : Embrapa-SPI, 1998. Cap.13. p.257-274.

RYU, E. Rapid microscopic agglutination test for leptospira without non-specific reaction. Bulletin Office of International Epizooties, v.73, p.49-58, 1970.

VAN TIL, L.D.; DOHOO, I.R. A serological survey of leptospirosis in prince Edward Island swine herds and its association with infertility. Canadian Journal Veterinary Research, v.55, p.352-355, 1991.

VASCONCELLOS, S.A. et al. Leptospirose bovina. Níveis de ocorrência e sorotipos predominantes em rebanhos dos Estados de Minas Gerais, São Paulo, Rio de Janeiro, Paraná, Rio Grande do Sul e Mato Grosso do Sul. Período de janeiro a abril de 1996. Arquivos do Instituto Biológico, v.64, p.7$15,1997$. 